\title{
ENGINEERS TEACHING COMMUNICATION: EVALUATING THE IMPACT OF TA TRAINING ON GRADUATE STUDENT COMMUNICATION, TEACHING AND PROFESSIONAL DEVELOPMENT
}

\author{
Nikita Dawe, Jeff Harris, Melanie Stevenson, Deborah Tihanyi \\ with \\ Narges Balouchestani Asli, Jordan Bouchard, Carolyn Busby, Vahid Shaayegan \\ University of Toronto \\ nikita.dawe@mail.utoronto.ca, jharris@mie.utoronto.ca, mel.stevenson@utoronto.ca, deborah.tihanyi@utoronto.ca
}

\begin{abstract}
The Engineering Communication Program works with engineering TAs in the Department of Mechanical and Industrial Engineering at the University of Toronto to deliver communication instruction in core design courses. Engineering TAs' disciplinary expertise affords increased credibility with students, and we have had consistent anecdotal evidence from TAs that teaching communication has made them better communicators. Currently, training involves a combination of instruction and mentorship, both from faculty and each other.

Here, we investigate TAs' increased confidence and skill in communication and teaching: what they find useful, how the training has influenced their communication and teaching practice, and what more they would like to explore in the future. An initial survey and discussion found that confidence was shaped by experience, course-specific training, instructor feedback, and peer learning. We hope to build on these findings in future through a broader study of TAs in the Faculty and further development of our TA training programs.
\end{abstract}

Keywords: graduate engineering education, professional development, teacher training, communication

\section{INTRODUCTION}

\subsection{Background}

The Engineering Communication Program (ECP) works to integrate communication into the core curriculum across the Faculty of Applied Science and Engineering (FASE) at the University of Toronto (U of T). As such, our faculty-although typically with humanities or social science backgrounds-collaborate closely with engineering colleagues to understand disciplinary communication needs. Communication instruction is not seen as something separate from, or in addition to, engineering work, but something that is inherent in that work. As a result, ECP stresses training for our instructors; while they may have expertise in communication and rhetoric, they require guidance in and exposure to the unique contents and contexts within engineering.

In the Department of Mechanical and Industrial Engineering (MIE), communication teaching and learning happens within the design spine across all four years of the undergraduate degree. Currently, ECP works with MIE faculty and TAs (all engineering graduate students) in eight courses, facilitating all aspects of communication instruction, including developing classroom activities, assignments, and assessment tools. When we initially became involved with MIE, we made a conscious effort to more thoroughly engage engineering faculty - and, in particular, TAs - in the development and delivery of that instruction. The thinking was that engineering TAs, with their disciplinary expertise, are in a unique position to understand disciplinary expectations around communication; moreover, that expertise affords increased credibility with students.

Given the importance of training in the ECP culture, it was natural to bring that into the work we do with MIE TAs. Over the past several years, we have heard repeatedly from TAs that teaching engineering communication has made them more effective communicators in their own work, and that the training around teaching communication has made them better/more confident teachers. What surprised us was the fact that the time we took in training-including workshops on specific topics, course-specific training and individual feedback - was not the norm in most TAs' experience in engineering courses. This surprise led us to want to investigate further the impact of training on graduate student communication, teaching and professional development, both in terms of the existing literature and among our own TAs. 


\subsection{Scanning the Literature}

In recent years, there has been an emphasis on the professional development of graduate student teaching assistants and the significant role they play in undergraduate engineering education. Research in this area highlights the importance of identity development among graduate student TAs, as they move from the role of novice to experienced practitioner [17], [11], [3]. Key in this process is the concept of teacher self-efficacy-the belief that, as a teacher, one can have an impact on students' learning and performance - and the relationship between that self-efficacy and achievement in teaching activities [15], [13]. At the K-12 level, Tschannen-Moran and Woolfolk Hoy [14] found that the availability of teaching resources and interpersonal support had a strong correlation to teachers' self-efficacy, with experienced teachers reporting higher self-efficacy around instruction and classroom management than their novice counterparts. At the post-secondary level, DeChenne and Enochs [4] found a correlation between training and selfefficacy in STEM graduate TAs, while Gilmore and Hurst [9] linked interpersonal support-from peers and faculty - to achievement in inquiry-based teaching skills.

In Canada, in 2015, the Teaching Assistant Graduate Student Advancement (TAGSA) special interest group (SIG) of the Society for Teaching and Learning in Higher Education (STLHE) published its "Framework for Teaching Assistant (TA) Competency Development" [12]. The Framework serves as a point of departure for teaching units across the country in promoting professional development among graduate student TAs, encouraging a four-step process of reflection on prior knowledge and experience, seeking insight into teacher identity and disciplinary and pedagogical knowledge, developing skills related to working in a university environment, and demonstrating professionalism and effective interpersonal communication. The TAGSA SIG identified the real need to distinguish $T A$ skills from more general graduate student professional development, noting that such a distinction is key to emphasizing the importance of teaching in the university context [10]. Memorial University of Newfoundland (MUN) has developed a number of training initiatives for their engineering graduate students along these lines, including graduate seminars, one-day intensives, mentorship programs, and online resources [1], [2]. The University of Victoria has created a training program for Design Engineering \& Instruction (DE \& I) TAs, which includes a three-day workshop series touching on design, mentorship, and developing design projects [6], [7]. The University of Toronto has added specific seminars based on unique types of tutorial contexts (Discussion-based sessions, Skill development sessions, Q\&A and review sessions, and Laboratories [16]); in FASE, these sessions complement an existing 3-hour introduction to teaching at
$\mathrm{U}$ of $\mathrm{T}$ for all new TAs, as well as existing initiatives in specific design courses [5], [8].

\subsection{Motivation}

Over the past two years, we have endeavoured to create a more rigorous training plan for MIE TAs involved in communication instruction. At its core, the training has a set of five communication principles (outcomes based on the Communication Graduate Attribute for CEAB) which focus on argument, organization, and clarity in written, oral, and visual communication. TAs receive training within their specific courses through a combination of teaching resources (on communication and pedagogy) and interpersonal support (team and individual meetings with ECP supervisors). This training addresses the development of classroom activities, assignments and assessment tools, engaging students in multiple contexts, and delivering effective feedback.

Our motivation for undertaking this study stems from wanting to build on the anecdotal evidence around our TAs' increased confidence in their communication and teaching skills. We wanted to explore what elements of the training they found useful, how that training has influenced their practices, and what more they would like to explore in the future. From this initial explorationdocumented here-we hope to build on our training program and engage in a wider study of TA training in FASE.

\section{METHODOLOGIES}

\subsection{Approach}

Given the complexities of pedagogical inquiry, our collaborative approach to teaching, and our desire for our research to feed back into our practice, we used a collaborative, iterative, mixed-methods approach. Thus, rather than begin with a full-scale study based on our existing assumptions - with TAs serving only as research subjects-we invited MIE TAs to collaborate with us from the start as co-investigators whose perspectives could shape and enrich an unfolding inquiry.

As a first step, Melanie Stevenson and Deborah Tihanyi (ECP's communication coordinators for MIE) sought active participation in developing an initial exploratory survey and follow-up discussion questions for ECP MIE TAs. This led to Nikita Dawe (MIE TA) and Jeff Harris (postdoctoral fellow and MIE course instructor) joining as principal investigators. After the survey and a five-person discussion group were completed, we shared the results with the discussion group, who provided further written commentary. Three 
of these TAs were given the opportunity to read and comment on a draft of this paper.

This approach not only provided some initial results, but equally important, allows us to develop, test, and refine research instruments to be used in a future, largerscale study.

\subsection{Demographics}

As our focus was on the impact of communication training on engineering TAs teaching in MIE at $U$ of T, we limited our study to those TAs ECP had supervised or collaborated with. We also limited it to the 27 TAs working with us in the current academic year (2015-16), as this was the year we introduced new online training resources. Participation in the study was voluntary, with participants offered an opportunity to co-author the resulting paper.

2.2.1. Survey Participant Demographics. Of the 13 survey respondents, 8 were $\mathrm{PhD}$ students, 4 MASc students, with a remaining 1 MEng student. The majority (11) were pursuing their degree in MIE; of the remainder, 1 was affiliated with Aerospace Studies and 1 with Electrical and Computer Engineering. Their degree of involvement in ECP varied: of the 13 TAs, 3 had TA-ed in five or more ECP-related courses, 2 in 3 courses, 2 in 2 courses, and 6 in one ECP course (note that here, "course" could mean a different course or multiple instances of the same course).

Regarding teaching expertise, the majority (11 of 13) had had some teaching experience before working with ECP, primarily through TA-ing engineering math, science, or design courses (7). The majority (10) also had some form of teacher training prior to ECP's, with the most common source FASE's three-hour TA training session. Only 4 respondents had training from the university-wide Teaching Assistants' Training Program (TATP), which offers more in-depth training than FASE, but is not engineering-specific. Only a minority of survey respondents (4) had received course-specific training in the past. Three (3) had come to ECP without any teacher training at all.

Regarding training in communication, a majority of respondents ( 9 of 13) had some university-based communication training prior to their ECP involvement. Only 4 had not. The most common form of training was a stand-alone communication course at the undergraduate level (6 respondents); the second most common was a stand-alone graduate communication course (4 respondents).

2.2.2. Discussion Group Demographics. The five discussion group participants self-selected from the initial MIE survey pool. While it may be reasonable to assume self-selectors shared a strong interest in teaching, in other respects they were a diverse group. It included 3 women and 2 men, two MASc and $3 \mathrm{PhD}$ students, and TAs with significant prior teaching and/or communication training and TAs with very little. All had at least minimal teacher training (e.g., 3 hours from FASE). Three of the five had no previous communication training.

\subsection{Survey}

The four principal investigators developed a questionnaire comprised of 36 questions, including fivepoint scales, checkbox, and short answers. Questions asked about TAs' demographic information, previous teaching experience and training, type of student interactions, response to ECP training, and views on their teaching roles and professional development (see Appendix A).

An invitation to participate in the survey was sent to all 27 engineering TAs trained by ECP and currently involved in teaching communication in MIE courses. Participants were given the option of responding anonymously or by name.

Of the 27 TAs contacted, 13 filled out the survey: 8 self-identified, while 5 opted to remain anonymous. All named survey respondents were then invited to participate in the follow-up discussion group.

From the survey data, we identified three main areas to be explored in more detail in the follow-up discussion group: the role of the TA, their source of confidence in teaching and communication, and their definition of effective engineering communication.

\subsection{Discussion Group}

Five survey respondents participated in the discussion group, which took place three weeks later. Prior to the meeting, participants were asked to respond to the following questions:

1. What is your role as a TA?

2. In the survey we asked about your confidence in teaching and professional communication. Where does your confidence come from?

3. Describe effective engineering communication. These three questions formed the basis for structuring the discussion, which took place over 1.5 hours and was facilitated by two of the non-TA principal investigators. The session was video-recorded, while a third non-TA investigator took notes.

After the meeting, a copy of the survey results was mailed to the discussion group participants (as well as a copy of the video recording of the discussion), who then had the opportunity to write down their subsequent thoughts and reactions and send them to the principal investigators via email. 


\section{RESULTS \& DISCUSSION}

Our initial analysis of the data involved identifying recurring themes in both the survey responses and discussion.

\subsection{Survey Results}

From the survey, we learned that the TAs who responded find ECP meetings (including teaching team meetings, one-on-one preparation meetings, and assessment meetings) useful overall. There was a notable increase in self-reported confidence in their communication abilities after their TAship with ECP. On a 5-point scale-with 1 being not very confident to 5 being very confident - the average rating increased from 3.9 to 4.3. This increase was attributed to experience (working with students) and interpersonal support (receiving coaching and mentorship from ECP supervisors). A similar increase (3.3 to 4.0) in teaching confidence was attributed to experience as a TA and interpersonal support.

\subsection{Discussion Group Results}

Interestingly, the TAs focused on their broader teaching experiences rather than their roles as engineers teaching communication. This focus informed the four prominent themes we identified in participants' remarks:

1. Identity development: participants noted a number of dualities, such as teacher/researcher and student/professor.

2. Lack of resources: participants commented that the mandatory TA training for all TAs in the university and/or FASE does not adequately prepare graduate students to teach.

3. Interpersonal relationships and feedback: TAs find individualized training (such as ECP teaching team meetings and mentorship) valuable as they learn how to teach and feel supported through interpersonal relationships.

4. Confidence and self-efficacy: experience is the main source of TA confidence.

\subsection{Theme 1: Identity Development}

Like faculty, graduate students serve the university as both researchers and teachers. TA identities are shaped by their experiences as undergraduates and their role models and mentors (research supervisors, teaching supervisors) during their graduate experience. Participants in our study care about their teaching, but they acknowledged cases of TAs who identify primarily as researchers and only TA because it is necessary.
The TAs who self-selected to participate in this study do consider their role as a teacher to be part of their identity and as a result they care about their impact on students. Most participants wanted to improve on the education that they had received as undergraduate engineering students, describing tutorials they had attended where the TAs had been incompetent and/or disinterested in their teaching duties; in other words, their own experience as an undergraduate has an impact on their motivation for development. This shows how TAs can identify with students and empathize with them, although they may not have been in that position for a number of years. The comments from participants mirror Sprague and Nyquist's (1989) graduate teaching assistant phases, moving from Senior Learners to Colleagues in Training to Junior Colleagues as they develop their professional identities [cited in 3]. The newer (and younger) TAs identify closely with students, while more experienced (and older) TAs noted that they identify more closely with faculty. Having said that, all participants saw themselves as a bridge between students and faculty. They try to be welcoming and informal with students, while still acting professionally and being conscious of appropriate boundaries. As well as being more approachable in their interactions with students, TAs highlighted their role in conveying feedback to faculty about what students were getting out of lectures.

\subsection{Theme 2: Resources}

Participants felt that the training provided by the university (TATP) and FASE is insufficient. They thought that the university-wide training lacks specificity for an engineering context, while the FASE training is focused primarily on the administrative/bureaucratic aspects of teaching rather than the pedagogical. As Mena [11] notes, generic training is necessary as TAs do need to be aware of the administrative and bureaucratic rules and requirements they will contend with. However, the participants went on to say that while TAs contribute to a significant portion of the undergraduate education, they do not feel prepared for this responsibility; there seems to be an assumption that since they are familiar with the course content they are prepared to teach it. Participants commented:

- $\quad$ II think given the significant role TAs play, and the degree to which they influence student success, it's amazing that there isn't more accountability in most courses."

- "I think it is funny that we are paid so much with so little TA related training."

- "Currently TA expectations are often limited to the tasks involved rather than how the tasks are carried out."

At ECP, we experimented this year with online teaching resources on a variety of topics, including 
communication principles, strategies for dealing with team conflict, and giving feedback. However, not all participants had even consulted these resources; those who did, used them minimally, if at all. Caines, Lye and Hussain's [2] recommendations based on MUN's engineering graduate TA training initiatives, including role-playing, faculty feedback, and mentorship, align with some of the training approaches our participants believe should be made available to all FASE TAs.

\subsection{Theme 3: Interpersonal Relationships and Feedback}

Participants agreed that the course-specific training and support they receive from ECP is much more valuable than the institution's training as they learn through relationships with peers and mentors, and receive timely, useful feedback.

Mena [11] notes that graduate teaching assistants value having someone with whom to discuss teaching issues and classroom tips more than having someone to discuss course content. One participant summarized the significance of interpersonal relationships, particularly peer learning from more experienced TAs, in her follow up email: "There was a lot to learn from other TAs as well as supervisors. In most cases the peer learning came from experienced TAs advising new TAs." These comments and observations are reflected in the literature. TAs value experienced peer mentors [2]; Gilmore and Hurst [9] found a connection between interactions with peers and improvements in (inquiry-based) teaching skills. ECP's teaching team meetings provide opportunities for TAs to share teaching challenges and strategies and learn from each other.

The survey and discussion showed that MIE TAs find feedback from ECP supervisors useful, but many would like even more feedback. During the discussion, participants highlighted how critical TA-instructor relationships are for expectations, confidence, accountability, and closing the feedback loop. One participant praised the feedback she received in ECP training: "I really liked the fact that by getting feedback from the instructor we were being held accountable for our work. Being held accountable pushes us to do our best, think about how we're teaching, and look for ways to improve." Similarly, the literature talks about the importance of mentorship, sometimes implying that TAs want but don't get enough interactions with instructors [13]. Feedback also helps to build TAs' self-confidence: "The feedback I have received from my students, supervisors and observers has led me to believe that I present and teach better than I thought."

\subsection{Theme 4: Confidence and Self-efficacy}

Based on the data, we saw that confidence in teaching increases with experience. In the discussion, participants noted that through experience TAs become more comfortable with the course material, they get to know what duties are expected of them, they have the opportunity to try out different teaching strategies, and they accumulate more feedback from students and faculty supervisors.

Experience as a TA in a course helped participants understand the instructor's expectations around how they needed do things (not just what they were expected to do). Participants bring this understanding into subsequent TA roles and feel more prepared as a result; as one participant said, "a lot of my confidence comes from having done it before, or something similar." Discussion participants also reported that being hired to TA again for the same course felt like confirmation from the instructor that they had done their job well, further increasing their confidence. In terms of feeling competent about the content they teach, participants liked to have taken the same or an equivalent course as a student and feel more confident if the course relates to their research area. Mena [11] similarly found that it is helpful for TAs to have previously taken the course as a student. This finding is of particular interest to ECP when engineers are teaching communication-a subject that is not necessarily within their realm of expertise.

Tschannen-Moran, Woolfolk Hoy, and Hoy [15] discuss self-efficacy in terms of self-perception of competence. The term 'self-efficacy' did not come up in the survey or discussion results; however, participants did make connections between self-confidence and competence. Furthermore, comments from our TAs seemed to touch on two of Bandura's (1997) four sources of efficacy expectations-master experiences and vicarious experiences [cited in 15]. It will be important to use self-efficacy assessment tools and explore the sources of self-efficacy further in our full-scale study.

\section{CONCLUSIONS AND FUTURE WORK}

At the University of Toronto, MIE graduate students are engaged as teaching assistants teaching engineering communication. Since engineering communication is often outside the core technical expertise of the TAs, we perhaps have a greater awareness of their training and development. This preliminary study investigated the impacts of TA training on graduate student communication, teaching and professional development, identifying four key themes: TA identity, resources, interpersonal relationships and feedback, and self-efficacy and confidence.

These preliminary findings will guide two threads of future work. The first will be a larger study on TA 
training within FASE at the University of Toronto. This educational research will expand our scope to a larger number of teaching assistants and more deeply investigate the topics identified in the present work. The second will improve our practice of TA development and training. Recommendations will be developed, implemented, and evaluated.

\subsection{Future Educational Research}

From our survey and group discussion, we found that confidence and self-efficacy were shaped by experience, course-specific training, instructor feedback, and peer learning. Among the TAs who participated in this study - only a subset of all TAs involved with ECP across FASE - a common theme was the desire for more training and feedback from instructors. These participants all considered teaching to be part of their identity, which may indicate an above-average interest in their professional development as an educator and a stronger desire for training and feedback than their peers. Therefore, we also intend to survey TAs involved with ECP across FASE and analyze their desire for additional training and feedback in terms of motivation, identity, and career goals. This broader approach will help identify whether the desire for more training and feedback is consistent across all TAs. A larger study will also allow for a closer examination of the connections between teaching resources, interpersonal support, and self-efficacy in both experienced and inexperienced TAs [14].

Since instructor feedback plays a key role in the development of TAs, we also intend to explore the mentor-mentee relationship between faculty and graduate students. Specifically, we wish to explore the extent to which faculty mentor graduate student TAs as teachers. In the discussion group, we heard that the existing mentor-mentee relationship focuses significantly more on research than on teaching. As one participant noted, "Not formally training TAs is likely a legacy of not having formally trained professors. They are experts in their fields, but not necessarily expert teachers."

\subsection{Improvements to Developing TAs}

Ultimately, we intend to improve TA training and the feedback instructors give to TAs within our existing institutional constraints. With respect to TA training, we found that there was a greater value given to in-person training than written online resources. Therefore, in the future, we will implement best practices, invest in more in-person TA training, and measure the impact of that training. Additionally, we intend to investigate the types of feedback that instructors give to TAs and the effectiveness of each type of feedback. Based on those results, we will be able to develop, implement, and evaluate additional mechanisms for instructors to provide feedback to TAs.

Moreover, peer learning currently plays a role in the development of teaching assistants even though there is no formal structure to facilitate peer mentorship. The current peer mentoring and learning occurs through informal conversations and discussions at teaching team meetings. Therefore, in the future, we will identify potential structures that could help facilitate peer mentorship, and we will investigate whether there is merit to implementing those specific structures.

\section{Acknowledgements}

We would like to acknowledge the TAs who collaborated with us in the various stages of this project: Narges Balouchestani Asli, Jordan Bouchard, Carolyn Busby, Michelle Cho, Carmen Chui, Yasamin Kazemi, Vahid Shaayegan

\section{References}

[1] Susan Caines and Leonard Lye, "Enhancing Learning Experiences of Graduate Students in the Faculty of Engineering and Applied Sciences at Memorial University of Newfoundland," in Proc. 2015 Canadian Engineering Education Association (CEEA15) Conf. (Hamilton, ON, McMaster University; 31 May - 3 June, 2015), 5 pp., 2015

[2] Susan Caines, Leonard Lye, and Mohammed Raju Hossain, "Teaching Assistant Training to Enhance Graduate Engineering Education," in Proc. 2014 Canadian Engineering Education Association (CEEA14) Conf. (Canmore, AB; 8 - 11 June, 2014), 4 pp., 2014.

[3] YunJung Cho, Myoungsook Kim, Marilla D. Svinicki, and Mark Lowry Decker, "Exploring teaching concerns and characteristics of graduate teaching assistants," Teaching in Higher Education, vol. 16, no. 3, pp. 267279, 2011.

[4] Sue Ellen DeChenne and Larry Enochs, "Measuring the Teaching Self-Efficacy of Science, Technology, Engineering, and Math Graduate Teaching Assistants," in Proc. American Educational Research Conference (Denver, CO; April 2010), 30 pp., 2010.

[5] Kathleen Denbeigh, Ali Vahit Esensoy, Penny Kinnear, Jason Li, Wilson Ma, Michelle MacArthur, Asmaa Maloul, Mario Milicevic, Aaron H. Persad, Farzan Sasangohar, Deborah Tihanyi, and Liang (Leon) Yuan, "Engineers Teaching Engineering Communication: Integrating Disciplinary Expertise into the Engineering Communication Curriculum," in Proc. Canadian Engineering Education Association (CEEA12) Conf. (Winnipeg, University of Manitoba; 17-20 June, 2012), 10 pp., 2012. 
[6] Flavio Firmani, Michael McWilliam, and Peter Wild, "Academic Impact and Personal Experience of Design Teaching Assistants in Undergraduate Courses," in Proc. Canadian Engineering Education Association (CEEA14) Conf., Canmore, AB; 8 - 11 June, 2014), 6 pp., 2014.

[7] Flavio Firmani, Michael McWilliam, Peter Wild, Michael McGuire, Nikolai Dechev, and Colin Bradley, "Training Program in Engineering Design for Graduate Teaching Assitants [sic]," in Proc. Canadian Engineering Education Association (CEEA13) Conf. (Montreal, QC; 17 - 20, 2013), 6 pp., 2013.

[8] Jason A. Foster, Robert Irish, Patricia Kristine Sheridan, Geoffrey S. Frost, and Alan Chong, "Developing Teams of Engineering Design and Communication FacilitatorInstructors," in Proc. 2012 Canadian Engineering Education Association (CEEA12) Conf. (Winnipeg, University of Manitoba; 17-20 June, 2012), 1 p., 2012.

[9] Joanna Gilmore and Melissa Hurst, “An Exploratory Study of Factors Influencing the Development of STEM Graduate Students' Teaching Skills," in Proc. National Association for Research on Science Teaching, 2010 (Philadelphia, PA; 24 March 2010), 18 pp., 2010.

[10] Cynthia Korpan, Suzanne Le-May Sheffield, and Roselynn Verwoord, "Teaching Assistant Competencies in Canada: Building a Framework for Practice Together," Collected Essays on Learning and Teaching, vol. VIII, pp. 219-230, 2015.

[11] Irene B. Mena, "Socialization Experiences Resulting from Engineering Teaching Assistantships at Purdue University," PhD dissertation, Purdue Univ., West Lafayette, IN, 2010.

[12] Teaching Assistant Graduate Student Advancement (TAGSA) SIG of the Society of Teaching and Learning in Higher Education (STLHE), "Framework for Teaching Assistant (TA) Competency Development," 2015, 4 pp. Available as of May 8, 2016 from http://www.stlhe.ca/wpcontent/uploads/2011/05/Framework-for-TACompetency-Development-2015.pdf

[13] Megan Tschannen-Moran and Anita Woolfolk Hoy, "Teacher efficacy: capturing an elusive construct," Teaching and Teacher Education, 17, pp. 783-805, 2001.

[14] Megan Tschannen-Moran and Anita Woolfolk Hoy, "The differential antecedents of self-efficacy beliefs of novice and experienced teachers," Teaching and Teacher Education, 23, pp. 944-956, 2007.

[15] Megan Tschannen-Moran, Anita Woolfolk Hoy, and Wayne K. Hoy, "Teacher Efficacy: Its Meaning and Measure," Review of Educational Research, vol. 68, no. 2, pp. 202-248, 1998.
[16] University of Toronto, "Report, Joint Working Group on Undergraduate Tutorials," 48 pp., 2014. Available as of May 8, 2016 from http://www.provost.utoronto.ca/Assets/Provost+Digital+ Assets/Provost/Provost+Digital+Assets/Provost/Reports/ $\underline{\text { Report }+ \text { of }+ \text { the }+ \text { Joint }+ \text { Working }+ \text { Group }+ \text { on }+ \text { Undergradu }}$ ate+Tutorials.pdf

[17] Stacy L. Young and Amy M. Bippus, “Assessment of Graduate Teaching Assistant (GTA) Training: A Case Study of a Training Program and Its Impact on GTAs,' Communication Teacher, vol. 22, no. 4, pp. 116-129, 2008.

\section{APPENDIX A: SURVEY QUESTIONS}

\author{
About You \\ 1. What is your current degree program? \\ 2. What is your current department? \\ 3. Previous teaching experience before ECP \\ involvement \\ 4. Previous teaching training \\ 5. Previous communication training \\ 6. How many ECP involvements have you had \\ (count each course as 1 )
}

\section{ECP Teaching Team Training}

7. Did you look at the teaching materials provided in the MIE online folder (Google Drive)?

8. If yes, when did you use the materials (check all that apply)?

9. If yes, how did you use the materials? Please indicate the context (when/where/with whom) and what you did.

10. What kinds of teaching team meetings have you had (check all that apply)?

11. If you had meetings to prepare/plan for classroom activities, how useful did you find these meetings?

12. If you had meetings to prepare for one-onone/one-on-team meetings, how useful did you find these meetings?

13. If you had meetings to prepare for assessment/feedback/grading, how useful did you find these meetings?

14. On the whole, how useful did you find these meetings in terms of preparing you for your teaching duties?

15. Briefly describe one skill/strategy you learned in one of these meetings that you haven't yet used, but that you would like to try. State what it is, who suggested it (ECP supervisor or fellow TA) and 
where/how you'd like to try it. (If you can't think of one, write "N/A".)

16. Briefly describe one skill/strategy you taught/shared with the teaching team during one of these meetings. State what it is, why you shared it and how you suggested using it. (If you can't think of one, write "N/A".)

17. What type of feedback on your teaching have you received from your ECP supervisor?

18. If you've received feedback, what was it about? 19. Thinking only about feedback on your classroom performance, how useful did you find this feedback? 20 . Thinking only about feedback on your personal interaction with students, how useful did you find this feedback?

21 . Thinking only about feedback on your written feedback to students, how useful did you find this feedback?

22. On the whole, how useful did you find this feedback in terms of preparing you for your teaching duties?

23. What did you find most useful in the feedback on your teaching from your ECP supervisor?

24. What would you have liked feedback about that you did not get from your ECP supervisor?

\section{Interaction with Students}

25. In what setting(s) do you interact with students?

26. What is your favourite setting to interact with students and why?

27. What is your least favourite setting to interact with students and why?

\section{Teaching Role and Professional Development} 28. Do you feel you're having an impact on the development of students' communication skills? 29. How confident were you in your professional communication skills as an undergraduate?

30 . How confident were you in your professional communication skills as a graduate student before this TA-ship?

31 . How confident are you in your professional communication skills now?

32. How confident were you in your teaching skills before working with ECP?

33. How confident are you in your teaching skills now?

34. If your level of confidence in your professional communication skills has changed, why/how do you think that happened?

35. If your level of confidence in your teaching skills has changed, why/how do you think that happened?

\section{Further Participation}

36. Are you interested in collaborating with us further-including discussion group/individual interview and creating the conference paper and presentation? 